overarching theme. Rather than being about disease, his tales are more about his patients' astonishing capacities to adapt — and even thrive - in radically transformed worlds. His books resonate because they reveal as much about the force of character as they do about neurology.

The Mind's Eye also relates how an Australian psychologist named Zoltan Torey, rendered blind at 21 by a splash of acid, cultivates his photographic memory to the point that he shocks his neighbours by replacing the gutters of his house alone at night. In another chapter, Canadian novelist Howard Engel discovers that his morning Globe and Mail has been rendered into Cyrillic or Korean; it is his brain, of course, that has been translated by a stroke. After years of exhausting effort to engage language in new ways - composing by dictation, learning to scan words by linking adjacent letters - the novelist teaches himself to write books again.

For Sacks, disorders of vision, including his own, open a window on the brain's surprisingly active role in the authoring of experience. While under treatment for the ocular melanoma, the neurologist undertook a series of fascinating self-experiments. In one exercise, for example, he tested the limits of his brain's ability to fill in temporary gaps in his visual field caused by radiation treatment. Sacks found that repetitive patterns such as brickwork, and even clouds and trees, readily appeared to preserve the illusion of a seamless panorama around him. Faces, however, were beyond the conjuring ability of his visual cortex. "I've learned that the brain is always busy," he told me in an interview last summer.

Thankfully, Sacks's tumour has not returned, but he is still learning to cope with the aftermath, including a possibly permanent loss of three-dimensional vision - a poignant turn of events for a proud member of the New York Stereoscopic Society.

To maintain his own sense of continuity in the face of these challenges, Sacks will have to draw inspiration from the patients he has written about for 40 years. "The problems never went away," he quotes Engel as saying, "but I became cleverer at solving them".

Steve Silberman is a writer based in San Francisco, California.

e-mail:digaman@sonic.net

\title{
Hitchers, outcasts and wasteland beauties
}

\author{
Sandra Knapp revels in a portrait of weeds as resilient \\ rebels shaped by our meddling with the wild.
}

$\mathrm{L}$ ike humans, weeds are pervasive, domineering and badly behaved. But they adopt these traits only in order to reproduce. As naturalist Richard Mabey explains in Weeds, they are an in-your-face example of evolution by natural selection: weeding benefits weeds by allowing those that evade the hoe to produce seeds that inherit the very characteristics that allowed escape; using herbicide causes weeds to become more resistant to such poisons.

Mabey weaves social history, psychology, literature and art into his clear rendering of plant biology. Explanations of evolution sit alongside explorations of flower symbolism in Shakespeare. This blend, familiar to fans of his earlier reflections on nature in the wild, broadens the book's scope to human attitudes to plants in general.

Indeed, the concept of a weed makes sense only in relation to people - they are plants that cause us trouble by growing where we don't want them. Most of the social connotations of weeds are negative: unruly, weak or aggressive. Yet these designations are fluid. Some plants, such as St John's wort (Hypericum perforatum) or hemp (Cannabis sativa), have passed from love to hate and back again. Others, such as autumn ladies' tresses (Spiranthes spiralis), are a rampant but admired invader of our lawns.

Some weeds considered ubiquitous today were once rare: rosebay willowherb (Epilobium angustifolium), depicted among the fine flora on the ceiling of the Natural History Museum in London, was described by some nineteenth-century botanists as a woodland plant 'not often met with in the wild state.' This magenta-flowered perennial carpeted the bombed areas of 1940s London, earning it the common name of fireweed. Its

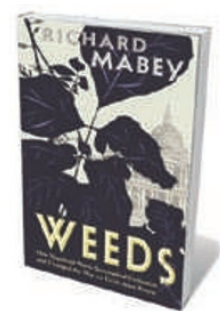

Weeds: How Vagabond Plants Gatecrashed Civilisation and Changed the Way We Think About

Nature

RICHARD MABEY

Profile Books: 2010

288 pp. £15.99 tiny seeds, carried on downy plumes, were dispersed by turbulence along railways; it now colonizes cities across Europe and North America. It is a good example of how weeds are a human construct, promoted by our tendency to disturb land.

Naturally invasive or easily transported species are also troublesome, particularly on islands with rare flora such as Hawaii, the Galapagos and Australia. For example, the velvet tree (Miconia calvescens) has taken over rainforest areas in Tahiti and is spreading on Hawaii; it chokes off native vegetation, preventing natural forest regeneration in these fragile habitats. But these plants arrived with people. Homo sapiens is the ultimate invasive species - coming out of Africa to colonize the globe, altering the planet beyond recognition.

Weeds highlights our ambivalence about naturalness and artificiality. We often think of pristine nature as the landscape we, or our grandparents, grew up with. Yet nature changes all the time. In the Pleistocene, much of northern Europe was covered with ice: no plants grew. Our entire flora is invasive, but that hasn't stopped us loving it.

Sandra Knapp is a botanist at The Natural History Museum, London SW7 5BD, UK.

e-mail:s.knapp@nhm.ac.uk

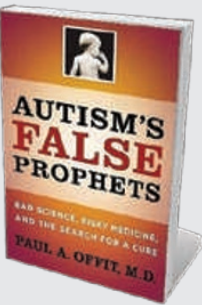

Autism's False Prophets

Paul A. Offit (Columbia Univ. Press, 2010; \$16.95) Vaccine expert Paul Offit digs beneath the unproven claims of links between autism and the measles-mumps-rubella vaccination, writing with "passion, authority, bluntness and literary skill", noted reviewer Jeff Thomas (Nature 455, 594-595; 2008).

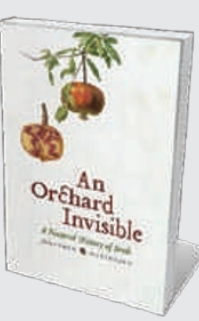

An Orchard Invisible: A Natural History of Seeds Jonathan Silvertown (Univ. Chicago Press, 2010; \$17) Seeds harbour essential aspects of the story of evolution, reveals ecologist Jonathan Silvertown. Looking beyond the familiar seeds and grains cultivated over centuries by humans for food, the book notes the unusual solutions taken by seeds to overcome survival challenges. 